\title{
Genetic manipulation of Salmonella serotype Bovismorbificans to aromatic-dependence and evaluation of its vaccine potential in mice
}

\author{
T. K. S. MUKKUR, B. A. D. STOCKER* and K. H. WALKERt
}

CSIRO Division of Animal Health. McMaster Laboratory, Private Bag No. 1, Glebe, New South Wales 2037, Australia, - Department of Medical Microbiology and Immunology, Stanford University School of Medicine, Stanford, California 94305-5402, USA, and +New South Wales Department of Agriculture and Fisheries, Elizabeth MacArthur Agricultural Institute, Regional Veterinary Laboratory, Menangle, New South Wales 2568, Australia

\begin{abstract}
Summary. The generation of smooth aromatic-dependent Salmonella serotype Bovismorbificans (Group $\mathrm{C} 2, \mathrm{O} 6,8)$ from a smooth wild-type parent strain by transduction with phage $\mathrm{P} 1$, and conjugation with Salmonella serotype Typhimurium carrying F'-8gal is described. The smooth aromatic-dependent $S$. serotype Bovismorbificans was non-lethal for mice at an oral challenge dose of $2 \times 10^{9} \mathrm{cfu}$ (equivalent to $200 \mathrm{LD} 50$ of the parent, wild-type strain). The safety of the auxotrophic mutant was further substantiated by comparing its multiplication kinetics in vivo with that of its virulent parent organisms. Mice immunised with live, smooth aromatic-dependent $S$. serotype Bovismorbificans by either the oral or intraperitoneal (i.p.) route were protected against oral challenge with virulent $S$. serotype Bovismorbificans; the degree of protection was significantly better $(p<0.05)$ at a challenge dose of 100 or $200 \mathrm{LD} 50$ in mice receiving two rather than one vaccination. In contrast, mice immunised with three doses of the formalin-killed virulent, parent organisms by the i.p. route were not protected, in spite of high antibody titres. Only those mice immunised with the live, smooth aromatic-dependent $S$. serotype Bovismorbificans i.p. developed significant $(\mathrm{p}<0.01-0.05)$ delayed-type hypersensitivity.
\end{abstract}

\section{Introduction}

Salmonellosis of ruminant animals is recognised as an important disease in most countries and causes serious economic losses, particularly in animals subjected to stressful conditions, such as those encountered during shipping over long distances ${ }^{1,2}$ or intensively-managed livestock enterprises. ${ }^{3}$ Furthermore, it constitutes a serious public health hazard not only for the consumers of meat and meat products but also for the worker associated with the handling of these products such as abattoir employees. ${ }^{4,5}$

Although a wide variety of Salmonella serotypes has been reported from outbreaks of clinical salmonellosis, most episodes can be attributed to a cluster of selected serotypes. The most common isolates from cases of salmonellosis in cattle in Australia, in order of frequency, are $S$. serotypes Dublin, Typhimurium, and Bovismorbificans. In sheep, they are $S$. serotypes Typhimurium, Bovismorbificans and Havana. ${ }^{2}$ Our aim is to develop a composite salmonella vaccine containing aromatic-dependent derivatives of the above-mentioned pathogens and to evaluate its effcacy in reducing the mortality of sheep during transit

Received 2 March 1990; accepted 16 May 1990. over long distances. Previously we reported that sheep immunised with $S$. serotype Typhimurium $\operatorname{aroA}$ by either the oral or intramuscular route were highly protected against oral challenge with virulent organisms. ${ }^{6}$ In this communication, we describe the manipulation of virulent $S$. serotype Bovismorbificans to aromatic-dependence and the vaccine potential of the $S$. serotype Bovismorbificans aroA thus generated in experimental murine salmonellosis as a model system in the first instance.

\section{Materials and methods}

\section{Bacterial strains and phage lysates}

Virulent $S$. serotype Bovismorbificans strain CS400/ SL5747 used in this investigation was isolated from a dead sheep. Other bacterial strains and phage lysates used in the generation of $S$. serotype Bovismorbificans aro $A$ are shown in table $\mathrm{I}$. The virulent parent strain and derivatives with mutation in the aro $A$ gene were maintained as cultures from Brain Heart Infusion Broth (BHI) in glycerol at $-70^{\circ} \mathrm{C}$ in a Biofreezer. Derivatives with mutations in the gal operon were characterised by determining the ability of mutant organisms to ferment galactose in MacConkey's agar 
Table I. Bacterial strains

\begin{tabular}{|c|c|c|}
\hline Strain no. & Description* & Origin or reference \\
\hline \multicolumn{3}{|c|}{ (a) Salmonella serotype Bovismorbificans } \\
\hline CS400/SL5747 & Wild-type, tetracycline-resistant & From fatal enteritis in sheep \\
\hline CS401/SL5750 & As SL 5747 but gale & From SL5747 by selection for resistance to 2-deoxygalactose \\
\hline CS402/SL5752 & As SL5750 but tetracycline-sensitive & From SL5750 by selection on Böchner medium ${ }^{10}$ \\
\hline CS403/SL5780 & $\begin{array}{l}\text { As SL5752 but CRR426 [aroA554::Tn10 (Tc- } \\
\text { sens) non-rev] zbj-903::Tn10 galE galT and/or } \\
\text { galK } \dagger\end{array}$ & $\begin{array}{l}\text { From SL } 5752 \text { by transduction from SL2838, with selection for } \\
\text { tetracycline-resistance }\end{array}$ \\
\hline CS404/SL5785 & $\begin{array}{l}\text { As SL5752 but CRR [aroA] CRR[zbj-903::Tn10 } \\
\text { (Tc-sens)] galE galT and/or galK }\end{array}$ & From SL5780 by selection on Böchner medium ${ }^{10}$ \\
\hline CS405/SL5794 & As SL5785 but $\mathrm{Gal}^{+}$because carrying $\mathrm{F}^{\prime}-8 \mathrm{gal}+$ & $\begin{array}{l}\text { From SL } 5785 \text { by conjugational cross with SL3550, with selection } \\
\text { for gal }+\end{array}$ \\
\hline \multicolumn{3}{|c|}{ (b) Salmonella serotype Typhimurium } \\
\hline SL1479 $\ddagger$ & $\begin{array}{l}\text { UCD108-11 CRR426 [aroA554::Tn10 (Tc-sens, } \\
\text { non-rev)] }\end{array}$ & $S$. serotype Typhimurium UCD aroA ${ }^{12}$ \\
\hline SL2838 & $\begin{array}{l}7471 \text { galE705 CRR426 [aroA554:: Tn10 (Tc-sens, } \\
\text { non-rev)] zbj-903::Tn10 }\end{array}$ & $\begin{array}{l}\text { P1-sensitive stable } \text { aro } A z b j:: \text { Tn10 strain used as transductional } \\
\text { donor }^{13}\end{array}$ \\
\hline SL3550 & LT2 trp metA galE $541 / \mathrm{F}^{\prime} 8 \mathrm{gal}+$ & See Reference 14 \\
\hline
\end{tabular}

* CRR, Tn10-generated complex rearrangement mutation causing phenotypic characters indicated in parenthesis: Tc-sens, sensitive to tetracycline; non-rev, unable to revert to aro $+; z b j:: \operatorname{Tn} 10$, silent insertion of $\mathrm{Tn} 10$ at minute 20 of chromosome (co-transducible with aroA).

† The failure of strain SL5780 to recover wild-type phage sensitivity pattern when grown with galactose (and glucose) is presumed to result from a coincidental mutation in the gal operon, affecting function of gene gal T or $\mathrm{galK}$ or both.

¥ Additional characters of these strains, not here relevant, omitted.

base with D-galactose $0.5 \%$ and were grown in $\mathrm{BHI}$ with D-galactose for preservation at $-70^{\circ} \mathrm{C}$.

\section{Generation of aromatic-dependent S. serotype Bovismorbificans}

Various steps used in the generation of aromaticdependent $S$. serotype Bovismorbificans are shown in table I and are discussed in the Results section.

\section{Determination of LD50}

The LD50 of the virulent $S$. serotype Bovismorbificans strain CS400/SL5747 was determined in BALB/c mice as described elsewhere. ${ }^{?}$

\section{Immunisation and challenge experiments}

BALB/c, female mice (6-8 weeks old) were immunised with $S$. serotype Bovismorbificans aroA (CS405/ SL5794) either orally (one or two doses of $10^{10} \mathrm{cfu} /$ mouse administered 7 days apart) or intraperitoneally (i.p.) (one dose of $10^{5} \mathrm{cfu} /$ mouse or two doses of $10^{5}$ and $10^{6} \mathrm{cfu}$ administered 7 days apart). Additional groups of mice were immunised i.p. with formalinkilled $S$. serotype Bovismorbificans (three doses of $10^{7}, 10^{8}$ and $10^{9} \mathrm{cfu}$ given at intervals of 7 days). All immunising doses were prepared by washing bacteria grown in BHI with sterile physiological saline and resuspension in the same diluent so that the total cfu to be administered was contained in a total volume of $0.5 \mathrm{ml}$. All mice (including unimmunised control mice) were challenged at 4 weeks post-immunisation with 20,100 or 200 LD50 of virulent $S$. serotype Bovismorbificans (CS400/SL5747) by gavage with $0.5 \mathrm{ml}$ of a culture grown in BHI with shaking at $37^{\circ} \mathrm{C}$ for $18 \mathrm{~h}$ and after adjustment of $\mathrm{pH}$ to $8 \cdot 5$. Mice were observed for 15 days after challenge and mortality was recorded. The number of mice in each group was 8-18.

\section{Determination of multiplication of $S$. serotype Bovismorbificans aro $A$ in vivo}

The kinetics of survival of $S$. serotype Bovismorbificans aro A (CS405/SL5794) in mice were determined after inoculation by the i.p. $\left(1 \times 10^{5} \mathrm{cfu} /\right.$ mouse $)$ or oral $\left(5 \times 10^{8} \mathrm{cfu} /\right.$ mouse) route, over a period of 27 days after inoculation. $S$. serotype Bovismorbificans aro $A$ were enumerated in liver, spleen, mesenteric lymph nodes (MLN) and intestine. Organs were homogenised with a Colworth Stomacher 400 , sterile physiological saline $(1.0 \mathrm{ml})$ was added and the homogenate was spread-plated for viable counts on BHI agar, with the exception of intestine samples for which Xylose Lysine Deoxycholate Medium (XLD) was used.

\section{Immunological procedures}

Antibody titres were determined by an enzymelinked immunosorbent assay. ${ }^{8}$ Antigen (100 $\mu \mathrm{g}$ of protein) used for coating the ELISA plates (M129B, Dynatech) was prepared by ultrasonication of virulent $S$. serotype Bovismorbificans followed by centrifugation at $27000 \mathrm{~g}$ to remove the cell debris. The ELISA titres were expressed as end-point antibody titres. The cut-off point was determined by an average of the optical densities at $405 \mathrm{~nm}$ for four antigen-free wells, with a high activity mouse-specific anti- $S$. serotype Bovismorbificans serum used at a dilution identical with the starting dilution of individual test samples. 
ELISA titres were the sample dilutions determined by interpolation from the cut-off point.

Cutaneous hypersensitivity was measured by injecting the ultrasonicated antigen preparation described above ( $10 \mu \mathrm{g}$ of protein in $5 \mu \mathrm{l}$ of saline) into the foot pads of four mice and measuring their thickness with vernier calipers $48 \mathrm{~h}$ after inoculation. Cutaneous hypersensitivity was calculated as the mean increase in the foot-pad thickness ( $\mathrm{mm}$ ) after antigen injection in one hind foot minus that obtained after injection of saline in the other hind foot, measured $48 \mathrm{~h}$ after injection.

\section{Statistical analyses}

The significance of differences between mean $\log _{10^{-}}$ transformed values for ELISA titres and hypersensitivity measurements was determined by Student's $t$ test. Significance of protection in the mouse immunisation and challenge experiments was assessed by Fisher's Exact test.

\section{Results}

\section{Generation of aromatic-dependent S. serotype Bovismorbificans aro $A$}

The wild-type strain of $S$. serotype Bovismorbificans, CS400/SL5747, was prototrophic, smooth (as indicated by resistance to rough-specific phages and by reaction with Salmonella $\mathrm{O}$ 6,8 serum) and sensitive to Felix $O$ phage; it was resistant to tetracycline. Salmonella of O groups other than A, B and D do not adsorb phage $P 22$ which, therefore, cannot be used to transduce genes to or from such strains. Another general transducing phage, P1, is, generally, ineffective on smooth Salmonella strains but active on strains with the mutation galE, because when grown on medium not supplemented with galactose they make "rough" LPS of type Rc (galactose-deficient), appropriate for adsorption of phage P $1 .{ }^{9}$ Galactose-negative (non-fermenting) mutants of the wild-type $S$. serotype Bovismorbificans strain were, therefore, isolated by selection for ability to grow on defined medium containing 2-deoxygalactose, which inhibits the growth of galactose-positive strains. Two of 20 such mutants tested were resistant to Felix $O$ phage (indicating an LPS core defect) and sensitive to phage C21 which, like phage $P 1$, acts efficiently on strains making type Rc LPS. These two mutants were sensitive also to rough-specific phages $6 \mathrm{SR}$ and $\mathrm{Br} 60$. The presence of galactose (plus glucose, to prevent galactose toxicity) in the medium used for testing phage sensitivities restored the phage sensitivity pattern of the wild-type parent strain, indicating loss of galE function but retention of galK and galT functions, so that exogenous galactose could be used for synthesis of UDP galactose, the precursor of the galactose units of LPS. One of the two galE mutants, CS401/SL5750, was plated on autoclaved chloram- phenicol/fusaric-acid medium ${ }^{10}$ which impedes the growth of tetracycline-resistant Salmonella and Escherichia coli strains. Nine of 10 resistant mutants from this selection were found to be tetracycline-sensitive. One of them, CS402/SL5752, was treated with phage P1 grown on an $S$. serotype Typhimurium strain, SL2328, which is galE and has a transposon-generated non-reverting mutation at aro $A$ and an adjacent silent Tn10 insertion, $z b j-903:: T n 10 .{ }^{11}$ Selection was made for tetracycline resistance. One of 34 tetracyclineresistant colonies tested was found to be aromaticdependent by co-transduction of aro $A$ of the donor with its Tn10 insertion. This transductant, CS403/ SL5780, had the same phage-sensitivity pattern as its parent, which showed that it still had the galE mutation, but its phage sensitivities were not altered when tested on galactose-supplemented medium. This probably indicates that it had lost galK or galT functions, or both, by a second mutation affecting the $\mathrm{gal}$ operon. As tetracycline resistance is not desirable in a live vaccine strain, a tetracycline-sensitive mutant, CS404/SL5758, was next isolated from CS403/SL5780 by the same method as before. Finally, to restore wildtype LPS character (smooth), strain CS404/SL5780 was given an $\mathrm{F}^{\prime}$ factor, $\mathrm{F}^{\prime} 8$, which includes the gal+ operon of $E$. coli, by a conjugational cross with a $S$. serotype Typhimurium strain carrying this plasmid. A galactose-positive transconjugant, now smooth by the criterion of phage sensitivity pattern and $O-$ antigen character and still aromatic-dependent, was labelled CS405/SL5794. This strain was employed as a live vaccine in the trials. No reversion to aromaticindependence has been detected in strain CS405/ SL5794, as was to be expected since its transposongenerated aro $A$ mutation, originally used to construct a $S$. serotype Typhimurium live vaccine strain, SL1479, has given no revertants in extensive trials of that strain. ${ }^{12}$

Strain CS405 did not produce galactose-negative segregants at a rate detectable by streaking broth cultures on MacConkey agar base with added galactose, indicating either a fairly stable maintenance of the $F^{\prime}$ factor in this strain or, less probably, recombination of the wild-type $\mathrm{gal}^{+}$(of E. coli origin) of the $\mathrm{F}^{\prime}$ factor with the mutant gal region of the salmonella chromosome.

\section{In-vivo safety of various derivatives of $S$. serotype Bovismorbificans in mice}

The oral LD50 of the parent virulent $S$. serotype Bovismorbificans (CS400/SL5747) was calculated to be $1 \times 10^{7} \mathrm{cfu}$. As can be seen from table II, a significant percentage of mice survived when challenged with 200 LD50 dose-equivalents of that calculated for the wild-type $S$. serotype Bovismorbificans, i.e., $2 \times 10^{9}$ cfu of the galE (CS402/SL5752), galE galK and/or galT, aroA (CS404/SL5785) or aroA $\mathrm{Gal}^{+}$ (CS405/SL5794) smooth derivatives of $S$. serotype Bovismorbificans. 
Table II. Relative safety in vivo of $S$. serotype Bovismorbificans derivatives administered to mice by the oral route

\begin{tabular}{lcc}
\hline \multicolumn{1}{c}{ Derivative } & $\begin{array}{c}\text { Challenge } \\
\text { dose } \\
\text { (cfu) }\end{array}$ & $\begin{array}{c}\text { Total number of mice } \\
\text { surviving (\%)/total } \\
\text { number challenged }\end{array}$ \\
\hline $\begin{array}{l}\text { galE (CS402/SL5752) } \\
\text { galE galT and/or galK, aroA } \\
\text { (CS404/SL5785) }\end{array}$ & $2.0 \times 10^{9 *}$ & $8(67) / 12$ \\
$\begin{array}{l}\text { aroA Gal }{ }^{+} \text {(CS405/SL5794) } \\
\text { Wild-type, parent }\end{array}$ & $2.0 \times 10^{9}$ & $12(100) / 12$ \\
\hline
\end{tabular}

* $2.0 \times 10^{9}$ cfu represent 200 LD50 dose-equivalents of that calculated for the wild-type parent organism.

The safety of $S$. serotype Bovismorbificans aroA (CS405/SL5794) in vivo was further substantiated by comparing its multiplication kinetics in vivo with that of its virulent parent when administered by oral or i.p. routes. As shown in table III, $S$. serotype Bovismorbificans aroA $\mathrm{Gal}^{+}$(CS405/SL5794) was present in the liver, spleen, MLN and intestine (only in small numbers) regardless of the route of administration. By day 27 after oral administration, the mutant organisms were detectable in the intestine (in small numbers) but not in liver, spleen or MLN. On the other hand, when the organisms were administered by the i.p. route, the mutant aroA organisms were detectable in the spleen and MLN (not liver or intestine) of one out of three mice, but only by enrichment cultures. When mice were inoculated with the virulent parent organisms (CS400/SL5747) by the oral route, the organisms were detectable by direct plating on day 1 in the intestine. By day 4 they were detectable by direct plating in all organs and the total cfu showed a significant increase on day 7 . On day 14 , the total cfu showed a decline but one out of three mice had died. The remaining inoculated mice died on day 16 and no more animals were available for enumeration of organ counts. When
Table III. Multiplication of $S$. serotype Bovismorbificans aro A Gal + strain (CS405/SL5794) in vivo in mice inoculated by oral or i.p. routes

\begin{tabular}{|c|c|c|c|c|}
\hline \multirow{2}{*}{$\begin{array}{l}\text { Day after } \\
\text { inoculation }\end{array}$} & \multicolumn{4}{|c|}{ Mean cfu (SD)/organ in } \\
\hline & liver & spleen & MLN & intestine \\
\hline \multicolumn{5}{|l|}{ Oral route } \\
\hline 1 & $0\left[1 / 3 \mathrm{E}^{*}\right]$ & 0 & $0[1 / 3 E]$ & $58(50) \times 10^{3}$ \\
\hline 4 & $17(29)$ & $0[1 / 3 E]$ & $33(50)$ & $0[3 / 3 \mathrm{E}]$ \\
\hline 7 & $407(352)$ & $87(78)$ & $33(33)$ & $3.74(5 \cdot 2) \times 10^{3}$ \\
\hline 14 & $17(29)$ & $20(35)$ & $87(64)$ & $0[3 / 3 \mathrm{E}]$ \\
\hline 27 & 0 & 0 & 0 & 60 \\
\hline \multicolumn{5}{|l|}{ I.p. route } \\
\hline 1 & $105[1 / 3 \mathrm{E}]$ & $4[2 / 3 \mathrm{E}]$ & $133(188)$ & $0[1 / 3 \mathrm{E}]$ \\
\hline 4 & $83(76)$ & $70[1 / 3 E]$ & $107(159)$ & $70(32)$ \\
\hline 7 & $7(3)$ & $48[1 / 3 E]$ & $167(148)$ & $0[3 / 3 \mathrm{E}]$ \\
\hline 14 & $17(29)$ & $20(35)$ & $87(64)$ & $0[3 / 3 E]$ \\
\hline 27 & 0 & $0[1 / 3 E]$ & $0[1 / 3 E]$ & 0 \\
\hline
\end{tabular}

* E denotes recovery of salmonella organisms by an enrichment procedure whereas the figures shown within [ ] represent the proportions of mice from the organs of which salmonella organisms were isolated by enrichment culture.

mice were inoculated i.p. with the virulent parent, the organisms were detected by direct plating on day 1 from the liver, spleen, MLN and intestine. The total number of cfu increased in these organs on day 4. By day 7 after inoculation, all but two mice were dead (table IV).

\section{Immunisation-challenge experiments}

Table $\mathrm{V}$ shows that immunisation of mice with three doses of formalin-killed virulent $S$. serotype Bovismorbificans imparted no protection against oral challenge with virulent organisms. In contrast, mice immunised with live $S$. serotype Bovismorbificans aroA $\mathrm{Gal}^{+}$(CS405/SL5794) by either the oral or i.p. route were significantly protected. Protection appeared to be better in mice immunised with two doses

Table IV. Multiplication of the parent virulent $S$. serotype Bovismorbificans (CS400/SL5747) in vivo in mice inoculated by oral or i.p. routes

\begin{tabular}{|c|c|c|c|c|}
\hline \multirow{2}{*}{$\begin{array}{l}\text { Day after } \\
\text { inoculation }\end{array}$} & \multicolumn{4}{|c|}{ Mean cfu (SD) $\left(10^{3}\right) /$ organ in } \\
\hline & liver & spleen & MLN & intestine \\
\hline \multicolumn{5}{|l|}{ Oral route } \\
\hline 1 & 0 & 0 & $0\left[3 / 3 E^{*}\right]$ & $23 \cdot 4(26 \cdot 10)$ \\
\hline 4 & $2 \cdot 03(1 \cdot 13)$ & $2 \cdot 6(2 \cdot 0)$ & $6 \cdot 2(3 \cdot 6)$ & $9967(7596)$ \\
\hline 7 & $2180 \cdot 1(3484 \cdot 7)$ & $48 \cdot 3(52 \cdot 7]$ & $10 \cdot 0(7 \cdot 65)$ & $91667(70868)$ \\
\hline 14 & $832 \cdot 5$ & $9 \cdot 6$ & 1.95 & 78000 \\
\hline \multicolumn{5}{|l|}{ I.p. route } \\
\hline 1 & $0.11(0.047)$ & $0.05(0.029)$ & $0.029(0.22)$ & $0.09(0.03)$ \\
\hline 4 & $171 \cdot 3(129)$ & $285(208)$ & $77(77)$ & $23 \cdot 3(31 \cdot 3)$ \\
\hline 7 & 1565 & 1245 & 588 & 1587 \\
\hline
\end{tabular}

* Isolation by enrichment; the proportion shown in [ ] represents the number of mice in which salmonellae were isolated by enrichment divided by the total number of mice used on that day after inoculation.

$\dagger$ Average of two mice only because no more mice were alive after this interval. 
Table V. Protection of mice immunised with $S$. serotype Bovismorbificans aro $A \mathrm{Gal}^{+}$ strain (CS405/SL5794) against oral challenge with virulent organisms (CS400/SL5747)

\begin{tabular}{|c|c|c|c|c|c|}
\hline \multirow[b]{2}{*}{ Vaccine preparation } & \multirow{2}{*}{$\begin{array}{l}\text { Route of im- } \\
\text { munisation }\end{array}$} & \multirow{2}{*}{$\begin{array}{c}\text { Number of } \\
\text { vaccine doses } \\
\text { administered }\end{array}$} & \multicolumn{3}{|c|}{$\begin{array}{l}\text { Number of mice surviving }(\%) / \\
\text { total number of mice challenged with }\end{array}$} \\
\hline & & & 20 LD50 & 100 LD50 & 200 LD50 \\
\hline None (unimmunised) & NA & NA & $2(13) / 15$ & $0(0) / 16$ & $0(0) / 16$ \\
\hline $\begin{array}{l}\text { Formalin-killed virulent, } \\
\text { parent (CS400/SL5747) }\end{array}$ & I.p. & 3 & $2(25) / 8$ & $0(0) / 8$ & $0(0) / 8$ \\
\hline \multirow{4}{*}{$\begin{array}{l}\text { Live, derivative, aro } \\
\text { (CS405/SL5794) }\end{array}$} & I.p. & 1 & $15(83) / 18 \dagger$ & $8(44) / 18^{*}$ & $7(39) / 18^{\prime}$ \\
\hline & I.p. & 2 & $8(100) / 8 \dagger$ & $12(75) / 16 \S$ & $12(71) / 17$ \\
\hline & Oral & 1 & $6(75) / 8^{*}$ & $3(30) / 10$ & $2(20) / 10$ \\
\hline & Oral & 2 & $7(87) / 8^{*}$ & $6(75) / 8$ & $3(38) / 8$ \\
\hline
\end{tabular}

NA, not applicable.

Significance of protection in immunised $v s$. unimmunised mice $: \mathrm{p}<0.001 ; \uparrow \mathrm{p}<0.01 ; \mathrm{p}<0.05$.

rather than one dose. This was particularly evident at challenge doses of 100 and 200 LD50 (table V). The percentage survival of unimmunised control mice in the above experiments ranged from $0 \%$ to $13 \%$. It is interesting that mice surviving immunisation with the galE mutant of $S$. serotype Bovismorbificans (CS402/ SL5752) were significantly $(\mathrm{p}<0.01)$ protected against challenge-infection with the virulent parent, but mice immunised with the galE galK and/or galT mutant aro $A$ strain (CS404/SL5785) were not (data not shown).

\section{Immunological response}

Mice immunised with either two doses of live mutant (CS405/SL5794) or three doses of formalinkilled virulent organisms by the i.p. route developed high antibody ELISA titres, whereas those immunised with one dose of live mutant organisms by the i.p. route had low antibody titres (table VI). On the other hand, no antibody titres were detectable in mice immunised orally with one or two doses of the mutant
aroA strain. Mice immunised with the live, $S$. serotype Bovismorbificans aroA (CS405/SL5794) by the i.p. route (one or two doses) developed a significant cutaneous hypersensitivity which was determined to be characteristic of a delayed-type hypersensitivity response (i.e., type IV cell-mediated immune response represented by a predominantly lymphocytic infiltration, determined histologically). Those immunised by the oral route or with formalin-killed virulent parent organisms did not show this response (table VI).

\section{Discussion}

Recent experiments in our laboratory revealed that while mice immunised with $S$. serotype Typhimurium aroA, administered either orally or parenterally, were partially protected against experimental challenge infection with virulent $S$. serotype Bovismorbificans, sheep immunised orally were unprotected (Mukkur and Walker, unpublished data). Therefore, it was

Table VI. Immunological response of mice immunised with either live $S$. serotype Bovismorbificans aroA $\mathrm{Gal}^{+}$strain (CS405/SL5794) or formalinkilled virulent parent organisms 4 weeks after immunisation

\begin{tabular}{|c|c|c|c|c|}
\hline Vaccine strain & $\begin{array}{l}\text { Route of immu- } \\
\text { nisation }\end{array}$ & $\begin{array}{c}\text { Number of } \\
\text { vaccine doses }\end{array}$ & $\begin{array}{l}\text { ELISA titre } \\
\text { (units/ml, } \\
\text { SEM) }\end{array}$ & $\begin{array}{l}\text { Cutaneous } \\
\text { hypersensitivity } \\
\text { (mm, SEM) }\end{array}$ \\
\hline $\begin{array}{l}\text { Live CS405/ } \\
\text { SL5794 }\end{array}$ & i.p. & 1 & $1126(236)^{\mathrm{a}}$ & $0.57(0.12)^{d}$ \\
\hline $\begin{array}{l}\text { Live CS405/ } \\
\text { SL5794 }\end{array}$ & i.p. & 2 & $20094(9860)^{b}$ & $0.86(0.08)^{e}$ \\
\hline $\begin{array}{l}\text { Live CS405/ } \\
\text { SL5794 }\end{array}$ & Oral & 1 & Not detectable & ND \\
\hline $\begin{array}{l}\text { Live CS405/ } \\
\text { SL5794 }\end{array}$ & Oral & 2 & Not detectable & $0.17(0.02)^{f}$ \\
\hline $\begin{array}{l}\text { Formalin-killed } \\
\text { CS400/SL5747 }\end{array}$ & i.p. & 3 & $11767(3958)^{c}$ & $0.20(0.07)^{9}$ \\
\hline None & Unimmunised & NA & Not detectable & $0 \cdot 13(0.05)$ \\
\hline
\end{tabular}

ND, not done. NA, not applicable

Values significantly different from each other: b vs. a $(\mathrm{p}<0.01) ; \mathrm{c} v s . \mathrm{a}(\mathrm{p}<0.001)$; vs. $\mathrm{f}$ and $\mathrm{g}(\mathrm{p}<0.05)$; e vs. f and $\mathrm{g}(\mathrm{p}<0 \cdot 01)$. 
considered necessary to generate $S$. serotype Bovismorbificans aro $A$ by genetic manipulation and to evaluate its vaccine potential in mice in the first instance. Whereas the O-specific phage P22 has been used to transduce genes from one Salmonella strain to another within or between Groups A, B and D, the generalised transducing phase $\mathrm{P} 1$ was used for transduction of genes from $S$. serotype Typhimurium aro $A$ made galE to $S$. serotype Choleraesuis (Group C1) made galE. ${ }^{11}$ In this investigation, this process led to the generation of aroA, galE galK and/or galT derivatives (CS404/SL5785 or 5786) which were rough. However, the aroA strain CS404/SL5785 could be made $\mathrm{Gal}^{+}$and smooth by conjunction with $S$. serotype Typhimurium carrying F'8-gal (SL3550).

Regardless of the route used for the immunisation of mice, the rough strain (CS404/SL5785) did not impart any protection (data not shown) whereas the aro $\mathrm{A} \mathrm{Gal}^{+}$strain (CS405/SL5794) imparted significant $(\mathrm{p}<0.001-0.05)$ protection. The percentage protection obtained was significantly better $(p<0.05)$, particularly at a challenge dose of 100 or 200 LD50 when mice were vaccinated more than once. Mice immunised with live, $S$. serotype Bovismorbificans aro $A$ $\mathrm{Gal}^{+}$by the oral route or formalin-killed virulent

\section{References}

1. Jelinek PD, Franklin DA, Iveson JB. The recovery of salmonella from sheep that died during transportation by ship. Aust $V$ et $J 1982$; 58: 170-171.

2. Richards RB, Norris RT, Dunlop RH, McQuade NC. Causes of death in sheep exported live by sea. Aust Vet $J 1989$; 66: 33-38.

3. Wray C, Sojka WJ. Reviews of the progress of dairy science: bovine salmonellosis. J Dairy Rs 1977; 44: 383-425.

4. Smeltzer T, Thomas R, Collins G. Salmonellae on posts, handrails and hands in a beef abattoir. Aust Vet $J 1980 ; 56$ : 184-186.

5. Samuel JL, Eccles JA, Francis J. Salmonella in the intestinal tract and associated lymph nodes of sheep and cattle. $J$ Hyg (Camb) 1981;87:225-232.

6. Mukkur TKS, McDowell GH, Stocker BAD, Lascelles AK. Protection against experimental salmonellosis in mice and sheep by immunisation with aromatic-dependent Salmonella typhimurium. J Med Microbiol 1987; 24: 11-19.

7. Litchfield JT, Wilcoxon F. A simplified method of evaluating dose-effect experiments. J Pharmacol Exp Ther 1949; 96: 99-113.

8. Engvall E, Perlmann P. Enzyme-linked immunosorbent assay, ELISA. III. Quantitation of specific antibodies by enzyme- parent (CS400/SL5747) did not develop any delayedtype hypersensitivity, whereas those immunised with the live, aro A Gal ${ }^{+}$strain (CS405/SL5794) by the i.p. route showed a significant development. Since elicitation of delayed-type hypersensitivity is an indicator of cell-mediated immune response, the failure of the formalin-killed vaccine to impart protection against salmonellosis confirmed a role for cellular immunity in the prevention of this disease, as suggested previously. ${ }^{15}$ However, since mice immunised by the oral route which did not develop any delayed-type hypersensitivity were also protected, an important role for the localised cellular or humoral immune factors, or both, was also indicated. Although the nature of these local protective factors is not known at the present time, similar observations were made previously in sheep immunised with $S$. serotype Typhimurium aro $A$ by the oral route. ${ }^{6}$

This project was supported financially by the Rural Credits Development Fund, Reserve Bank of Australia and by an award made to T.K.S.M. by the Department of Science (now Industry, Technology and Commerce), Canberra, under the US/Australia Bilateral Science and Technology Agreement. The authors express their sincere thanks to Ms Marion Jamieson for excellent technical assistance.

labeled anti-immunoglobulin in antigen-coated tubes. $J$ Immunol 1972; 109: 129-135.

9. Ornellas EP, Stocker BAD. Relation of lipopolysaccharide character to $\mathrm{P} 1$ sensitivity in Salmonella typhimurium. Virology 1974; 60: 491-502.

10. Bochner BR, Huang H-C, Schieven GL, Ames BN. Positive selection for loss of tetracycline resistance. $J$ Bacteriol $1980 ; 143$ : 926-933.

11. Nnalue NA, Stocker BAD. Tests of the virulence and livevaccine efficacy of auxotrophic and galE derivatives of Salmonella choleraesuis. Infect Immun 1987; 55: 955-962.

12. Smith BP, Reina-Guerra M, Hoiseth SK et al. Aromaticdependent Salmonella typhimurium as modified live vaccines for calves. Am J Vet Res 1984; 45: 59-66.

13. Nnalue NA, Stocker BAD. The effects of $O$-antigen character and enterobacterial common antigen content on the invivo persistence of aromatic-dependent Salmonella sp. livevaccine strains. Microb Pathog 1987; 3: 31-44.

14. Kuo T-T. Genetics of Salmonella typhimurium: rough mutants, transduction by phage ES18 and suppression of proline auxotrophy. Ph.D. Thesis, Stanford University, California. 1969: $210 \mathrm{pp}$.

15. Collins FM, Mackaness GB, Blanden RV. Infection-immunity in experimental salmonellosis. J Exp Med 1966, 124: 601619. 